\title{
Single incision versus conventional laparoscopic resection in gastrointestinal stromal tumors: a retrospective cohort analysis at a single tertiary care center
}

\author{
This article was published in the following Dove Press journal: \\ OncoTargets and Therapy \\ 12 June 2014 \\ Number of times this article has been viewed
}

Jing Kong

Shuo-Dong Wu

Yang Su

Ying Fan

China Medical University Shengjing Hospital, Shenyang,

People's Republic of China
Correspondence: Shuo-Dong Wu

China Medical University Shengjing Hospital, Shenyang, Sanhao Street, \#36, Liaoning I 10004 , People's Republic of China $\mathrm{Tel}+8624966$ I5I3 I2II

Email wushuodong_1980@163.com
Background: Single-incision laparoscopic surgery (SILS), an advanced form of minimally invasive surgery, has recently been used for surgical management of gastrointestinal stromal tumors (GIST). The literature comparing SILS to conventional laparoscopic surgery for treatment of this disease is limited. This study aimed to evaluate the feasibility and effectiveness of SILS compared with conventional laparoscopic resection for GIST.

Methods: A retrospective case-cohort study compared the benefits and outcomes of SILS and conventional laparoscopic partial gastrectomy for GIST. Between April 2008 and December 2012, 39 patients underwent laparoscopic gastrectomy for gastric stromal tumors in our department. All operations were performed by a single experienced surgeon. The medical records of these patients were reviewed retrospectively with regard to tumor size, operating time, and other clinical features.

Results: SILS resection was performed on 19 patients, whereas 20 patients had conventional laparoscopic resection. Compared with the conventional laparoscopic group, the operative time for the SILS group was shorter, but the time for recovery of gastrointestinal function and postoperative hospital stay for the SILS group was similar to that of the conventional laparoscopic group. No intraoperative or postoperative complications were recorded in either group.

Conclusion: Compared with the conventional laparoscopic procedure, SILS in gastric stromal tumors is as feasible and safe when performed by experienced surgeons.

Keywords: gastric stromal tumor, SILS

\section{Introduction}

Gastrointestinal stromal tumors (GIST) are potentially malignant tumors ${ }^{1}$ that often are treated by surgical resection. ${ }^{2}$ However, since extensive lymph node dissection is not necessary in the treatment of GIST, laparoscopic gastrectomy is becoming accepted as a safe and feasible surgical procedure for this disease because of favorable postoperative outcomes. In recent years, transumbilical single-incision laparoscopic surgery (SILS), although still in its initial stages, has been performed increasingly often for resection of small GIST because of its cosmetic advantage. However, the data concerning SILS treatment for GIST do not sufficiently address the potential advantages of SILS compared with conventional laparoscopy.

In this report, we reviewed and compared the cases of GIST that have been treated by either single-incision laparoscopic partial gastrectomy or conventional laparoscopic partial gastrectomy, using traditional instruments, in our institution. We assessed the 
safety and feasibility of SILS by evaluating its operative and postoperative outcomes.

\section{Materials and methods Patient data}

The criteria for patient selection in our department were as follows: the tumors were located at the fundus, body, greater gastric curvature, lesser gastric curvature, anterior wall, and posterior wall in the stomach (excluding the cardia and pylorus); the diameter of the lesion was less than $10 \mathrm{~cm}$; the patient had no history of abdominal operations or contraindications for laparoscopic surgery; and the patient gave informed consent before surgery.

Thirty-nine patients underwent laparoscopic surgery for GIST at Shengjing Hospital of China Medical University between April 2008 and December 2012. Nineteen patients, with a mean age of 54 years (range 23-73 years), were treated by SILS partial gastrectomy and are referred to as the SILS group. Twenty patients, with a mean age of 59 years (range 36-75 years), were treated with conventional laparoscopy and are referred to as the conventional group. We reviewed their records retrospectively. The first eight consecutive patients underwent conventional laparoscopy because of our lack of experience with SILS. However, as use of SILS developed, we performed it for more patients with GIST. In 12 cases, the conventional laparoscopic method was selected because of patient concerns about the single-incision laparoscopic operation. However, these 12 cases were also suitable for singleincision laparoscopy according to our criteria. Thereafter, patients were nonrandomly assigned to either conventional laparoscopy or SILS.

The diagnosis of GIST in all patients and the position of the tumors with regard to the gastric wall were established preoperatively with computed tomography (CT), gastroscopy, and ultrasonic endoscopy (EUS). Patients with tumors located at the cardia or pylorus required proximal or distal gastrectomy rather than partial gastrectomy and were therefore not included in this review. Also, patients with tumors larger than $10 \mathrm{~cm}$, as evaluated with EUS and CT preoperatively, were excluded. All laparoscopic operations were performed by the same experienced surgeon.

\section{Operative techniques}

All patients were placed in a supine posture with legs apart. The laparoscopic equipment and the monitor were placed above the patient's left shoulder. The surgeon stood between the patient's legs while the first assistant (camera operator) stood at the patient's right side.
A superficial incision, $1 \mathrm{~cm}$ long, was made vertically within the umbilical fold into which a $10 \mathrm{~mm}$ trocar was inserted for passage of the $10 \mathrm{~mm}$ video laparoscope and for connecting the insufflator.

In the conventional laparoscopic group, two $5 \mathrm{~mm}$ trocars (right upper abdomen) and one $12 \mathrm{~mm}$ trocar (left upper abdomen) were placed so that the three trocars formed an inverted equilateral triangle. For the SILS group, one $12 \mathrm{~mm}$ trocar was placed at the 2 o'clock position and two $5 \mathrm{~mm}$ trocars at the 10 o'clock position.

Partial gastrectomy was performed in all patients. To facilitate this procedure, the left lateral segment of the liver often needed to be retracted in order to adequately expose the stomach. In the SILS group, the liver was affixed to the diaphragm by the application of the tissue adhesive cyanoacrylate (Beijing Suncon Medical Adhesive Company, Beijing, People's Republic of China) sprayed onto its diaphragmatic surface. ${ }^{3}$

The operations were performed as we have described elsewhere. ${ }^{4}$ Intraoperative endoscopy was used to quickly and accurately identify the lesion. A flexible Endo-GIA ${ }^{\text {TM }}$ linear stapler (Covidien Ltd, Dublin, Ireland) was often used for cutting out the tumor including a rim of normal gastric tissue. Intact specimens were removed in a bag to avoid contamination of the abdominal cavity. In the SILS group, we often cut the connecting tissue between the $5 \mathrm{~mm}$ and the $12 \mathrm{~mm}$ trocar site to enlarge the incision and permit extraction of the sample. In the conventional group, the right $12 \mathrm{~mm}$ port site was enlarged and used for the extraction.

\section{Evaluation of clinicopathological variables}

Demographic data (age, sex, and body mass index), operative details (operative time, blood loss, and perioperative complications), recovery measurements (time to return of bowel function and hospital length of stay), and details of the specimen (tumor location, size, and grade) were analyzed based on the information obtained from the medical records. The preoperative CT and EUS localization of the tumors was confirmed at operation. Size and grade of the tumors were evaluated by pathological examination of the resected specimens, and the malignant risk of the tumors was evaluated as described by Fletcher et al. ${ }^{5}$

Our standard clinical practice included evaluating patients with imaging and endoscopy every 6 months for 5 years after operation in order to determine if there was recurrence. The adjuvant imatinib mesylate $\left(\right.$ Glivec $^{\circledR}$; Novartis International AG, Basel, Switzerland) was prescribed for patients with intermediate or high risk recurrence of tumors. 


\section{Statistical analysis}

Statistical analyses were performed using the Statistical Package for Social Science, version 17.0 (SPSS, Chicago, IL, USA). The chi-square test, Fisher's exact test, and Mann-Whitney $U$ test were used as appropriate. Data are presented as mean \pm standard deviation. $P$-value less than 0.05 was considered statistically significant.

\section{Results}

\section{Patient demographic and baseline characteristics}

Table 1 shows the demographic data of patients in the conventional and SILS surgery groups. Females were predominant in both groups. Tumor size and location were similar in the conventional and SILS groups. Tumors were found at several locations in the stomach (excluding the cardia and pylorus for the reason stated above): fundus, body, greater gastric curvature, lesser gastric curvature, anterior wall, and posterior wall. Tumors were most frequent in the fundus.

\section{Surgical outcomes}

All the patients underwent partial gastrectomy successfully. The only significant difference between the groups was

Table I Patient demographic data

\begin{tabular}{|c|c|c|c|}
\hline Factor & $\begin{array}{l}\text { Conventional } \\
\text { group }(n=20)\end{array}$ & $\begin{array}{l}\text { SILS group } \\
(n=19)\end{array}$ & $P$-value \\
\hline Age (years) & $59.7 \pm 10.6$ & $54.1 \pm 11.2$ & 0.316 \\
\hline Sex & & & 0.093 \\
\hline Male & $8(40 \%)$ & $3(15.8 \%)$ & \\
\hline Female & $12(60 \%)$ & $16(84.2 \%)$ & \\
\hline BMI & $20.7 \pm 1.4$ & $20.9 \pm 1.0$ & 0.532 \\
\hline Tumor site & & & 0.90 \\
\hline $\mathrm{F}$ & $8(40 \%)$ & 9 (47.4\%) & \\
\hline$B, G$ & $2(10 \%)$ & $3(15.8 \%)$ & \\
\hline$B, L$ & $5(25 \%)$ & 4 (2।.1\%) & \\
\hline A & I (5\%) & I (5.3\%) & \\
\hline$P$ & $4(20 \%)$ & $2(10.5 \%)$ & \\
\hline Tumor size $(\mathrm{cm})$ & $2.6 \pm 1.7$ & $2.8 \pm 1.7$ & 0.716 \\
\hline$<2.0$ & $10(50 \%)$ & $7(36.8 \%)$ & 0.641 \\
\hline $2.1-5.0$ & $9(45 \%)$ & 10 (52.6\%) & \\
\hline $5.1-10$ & I (5\%) & $2(10.5 \%)$ & \\
\hline$>10$ & 0 & 0 & \\
\hline Malignant risk & & & 0.916 \\
\hline Extremely low & 7 (35\%) & 7 (36.8\%) & \\
\hline Low & $10(50 \%)$ & $10(52.6 \%)$ & \\
\hline Intermediate & $3(15 \%)$ & $2(10.53 \%)$ & \\
\hline High & 0 & 0 & \\
\hline
\end{tabular}

Abbreviations: A, anterior wall of stomach; B, body of stomach; BMI, body mass index; F, fundus of stomach; G, greater gastric curvature; L, lesser gastric curvature; $\mathrm{P}$, posterior wall of stomach; SILS, single-incision laparoscopic surgery. in operative time, which was significantly shorter in the SILS group (99.0 \pm 14 minutes versus $112.2 \pm 24.5$ minutes, $P=0.045$ ). Although blood loss was less in the SILS group, the difference was not statistically significant $(49.5 \pm 15.4 \mathrm{~mL}$ versus $60.3 \pm 22.4 \mathrm{~mL}, P=0.09)$. Mean postoperative hospital stay was similar in both groups (Table 2). No cases in either group required conversion to open surgery, and no cases in the SILS group required conversion to conventional laparoscopic surgery. The surgical resection margins were free of tumor in all patients. No intraoperative or postoperative complications such as anastomotic leakage, bleeding, anastomotic stenosis, or incisional hernia occurred in any patient.

All 39 patients were ambulatory, with return of gastrointestinal function and ingestion of a liquid diet on the first postoperative day. Four patients in each group had intermediate-risk tumors and were given Glivec (400 mg/day) orally as adjuvant therapy for 1 year. During the median follow-up of 28 months, there was no evident recurrence of disease, based on endoscopic and CT findings, in either group.

\section{Discussion}

With the increasing use of endoscopy and EUS, stromal tumors in the stomach, including asymptomatic tumors less than $1 \mathrm{~cm}$, have been found frequently in our institution. Because the useful medicine Glivec is too expensive for many patients in China, it is recommended that GIST, after being conclusively identified through $\mathrm{CT}$, gastroscopic, and EUS examinations, be removed surgically. Because GIST rarely metastasize or spread beyond their macroscopic margins, local resection usually is effective treatment, and extended resection and regional lymph node dissection are not necessary. ${ }^{2}$

Since the introduction of laparoscopy in $1989,{ }^{6}$ this minimally invasive surgery has been applied widely to the treatment of benign and malignant gastric diseases. ${ }^{7}$ Many studies have shown that the laparoscopic approach is safe and effective for the treatment of GIST, with a short hospital stay and low morbidity. ${ }^{8,9}$ Technological advances and the

Table 2 Patient operative and postoperative data

\begin{tabular}{lccl}
\hline Characteristic & $\begin{array}{c}\text { Conventional } \\
\text { group }(\mathbf{n = 2 0})\end{array}$ & $\begin{array}{l}\text { SILS group } \\
(\mathbf{n = 1 9 )}\end{array}$ & P-value \\
\hline Operation time (minutes) & $112.2 \pm 24.5$ & $99 \pm 14$ & 0.045 \\
Blood loss (mL) & $60.3 \pm 22.4$ & $49.5 \pm 15.4$ & 0.09 \\
Hospital stay (days) & $12.3 \pm 2.6$ & $12.8 \pm 3.2$ & 0.529 \\
Recovery of bowel & $2.5 \pm 0.8$ & $2.2 \pm 0.9$ & 0.347 \\
function (days) & & & \\
\hline
\end{tabular}

Abbreviation: SILS, single-incision laparoscopic surgery. 
pursuit of less invasive methods have now made SILS an attractive option.

In fact, a few sporadic reports of GIST resection by SILS have been published in recent years; ${ }^{10-14}$ special equipment designed for single-port surgery and assisted small incision were useful in these cases. A $2 \mathrm{~mm}$ mini-loop retractor inserted through an extra incision through the left subcostal space was used to retract the stomach. In the report by Henckens et al, ${ }^{11}$ a Nathanson liver retractor was placed through the subxiphoid position and clinical prototypes of double-bended instruments and a "goose neck" video laparoscope were used. Specially designed instruments allowed relatively comfortable, intuitive manipulations. The total operating time was between 64 minutes and 140 minutes, and blood loss was small. The study illustrated that laparoendoscopic, single-site, partial resection of the stomach for GIST is feasible and a promising means of achieving scarless abdominal operations.

In our department, we have routinely used laparoscopic methods in the surgical treatment of small GIST. Following up on our successful use of SILS for cholecystectomy, appendectomy, herniorrhaphy, and colonic cancer resection, in 2009 we began using SILS for partial gastrectomy in the treatment of GIST with conventional instruments. In this review, the first eight cases were treated by conventional laparoscopic surgery rather than SILS because of our lack of experience with SILS. However, as use of SILS developed, we increasingly employed the procedure for more patients with GIST. Although there were 12 cases for which the conventional laparoscopic method was used because of concerns about the single-incision laparoscopic operation, these 12 cases were also suitable for the single-incision laparoscopic operation according to our criteria.

Our preliminary experiences in the 19 GIST cases demonstrated the safety and feasibility of the procedure, and there were no conversions to conventional laparoscopic surgery in the single-incision group. SILS is more challenging than multiple-incision laparoscopic surgery, especially with conventional instruments, because the instruments may be hidden from the field of view, there is no assistant, and the "chopsticks effect" can be an interference. However, placing the three trocars at the vertex of an inverted equilateral triangle about $10 \mathrm{~mm}$ apart may slightly prevent their colliding with each other. We also learned that the surgeon and camera operator must cooperate with each other by performing fine adjustments in order to ensure a smooth operation in the limited space. In the future, specially designed instruments may make the operation easier. ${ }^{10-14}$
When compared with conventional laparoscopic surgery, SILS can have favorable surgical outcomes with regard to operating time, blood loss, return of intestinal function, and length of hospital stay. The operative time from start to finish in our SILS group was shorter than that in the conventional group.

The following four factors are either conducive to successful SILS for gastric GIST or are technically advantageous: first, SILS is well-suited for operations on gastric tumors because the stomach has a large volume and is quite mobile. We have found SILS easy to carry out when the greater and lesser curvatures are freed from surrounding attachments with an ultrasonic scalpel. Also, the lesion can be quickly and accurately located, especially when intraoperative endoscopy is used. Second, the single umbilical incision for three trocars makes incising and suturing easier. Third, when the lesion was sufficiently exposed, we often found use of a flexible Endo-GIA linear stapler superior to artificial sutures for cutting out the tumor with a rim of normal gastric tissue. Use of the stapler simplifies the operation, whereas suturing and knotting are hampered by the chopsticks effect of SILS. Fourth, removal of the intact specimen in SILS can be easier than with conventional laparoscopy; enlarging the 10-12 mm trocar site for extracting the specimen is easier than enlarging the $12 \mathrm{~mm}$ port site in conventional laparoscopy.

Transumbilical SILS is still in its initial stage, but it has been performed for the treatment of GIST by several laparoscopic surgeons, and a small number of sporadic reports have been published. Our experience with a larger series supports the findings of those reports. We conclude that SILS partial gastrectomy for GIST smaller than 10 $\mathrm{cm}$ is feasible and safe when performed by experienced laparoscopic surgeons. In our experience, SILS can achieve the same outcome as conventional laparoscopic surgery and has the advantage of a shorter operation time. The limitation of the study is the lack of randomized selection, so the results may be biased. We are planning to carry out a randomized controlled trial to evaluate the clinical and economic outcomes, and are interested in performing long-term follow-up to fully define the benefits and risks of this new, minimally invasive technique.

\section{Disclosure}

The authors report no conflicts of interest in this work.

\section{References}

1. Joensuu H, Fletcher C, Dimitrijevic S, Silberman S, Roberts P, Demetri G. Management of malignant gastrointestinal stromal tumours. Lancet Oncol. 2002;3(11):655-664. 
2. Ng EH, Pollock RE, Munsell MF, Atkinson EN, Romsdahl MM. Prognostic factors influencing survival in gastrointestinal leiomyosarcomas. Implications for surgical management and staging. Ann Surg. 1992;215(1):68-77.

3. Fan Y, Wu SD, Kong J, Su Y, Tian Y. Transumbilical single-incision laparoscopic fundoplication: a new technique for liver retraction using cyanoacrylate. J Laparoendosc Adv Surg Tech A. 2013;23(4): 356-360.

4. Wu SD, Kong J, Su Y, Fan Y. Safety and application of transumbilical single-incision laparoscopic gastrectomy for GIST: SILS in benign gastric disease. Surg Innov. 2013;20(4):365-369.

5. Fletcher CD, Berman JJ, Corless C, et al. Diagnosis of gastrointestinal stromal tumors: a consensus approach. Hum Pathol. 2002;33(5): 459-465.

6. Nezhat C, Winer WK, Cooper JD, Nezhat F, Nezhat C. Endoscopic infertility surgery. J Reprod Med. 1989;34(2):127-134.

7. Liew V, Taylor C, Ghusn M, Jamnagerwalla M, Layani L. Laparoscopic gastric resection for benign and malignant conditions: lessons learned from 35 consecutive cases. ANZ J Surg. 2007;77(9):787-791.

8. DeMatteo RP, Lewis JJ, Leung D, Mudan SS, Woodruff JM, Brennan MF. Two hundred gastrointestinal stromal tumors: recurrence patterns and prognostic factors for survival. Ann Surg. 2000;231(1):51-58.
9. Huguet KL, Rush RM, Tessier DJ, et al. Laparoscopic gastric gastrointestinal stromal tumor resection: the mayo clinic experience. Arch Surg. 2008;143(6):587-590; discussion 591.

10. Hirano Y, Watanabe T, Uchida T, Yoshida S, Kato H, Hosokawa O. Laparoendoscopic single site partial resection of the stomach for gastrointestinal stromal tumor. Surg Laparosc Endosc Percutan Tech. 2010;20(4):262-264.

11. Henckens T, Van de Putte D, Van Renterghem K, Ceelen W, Pattyn P, Van Nieuwenhove Y. Laparoendoscopic single-site gastrectomy for a gastric GIST using double-bended instruments. J Laparoendosc Adv Surg Tech A. 2010;20(5):469-471.

12. Sasaki A, Koeda K, Nakajima J, Obuchi T, Baba S, Wakabayashi G. Single-incision laparoscopic gastric resection for submucosal tumors: report of three cases. Surg Today. 2011;41(1):133-136.

13. Takahashi T, Takeuchi H, Kawakubo H, Saikawa Y, Wada N, Kitagawa Y. Single-incision laparoscopic surgery for partial gastrectomy in patients with a gastric submucosal tumor. Am Surg. 2012;78(4): 447-450.

14. Dapri G, Ntounda R, Himpens J, Carnevali P, Scomersi S, Cadière GB. Single-incision transumbilical laparo-endoscopic gastric benign tumor resection. Ann Surg Oncol. 2011;18(1):191.
OncoTargets and Therapy

\section{Publish your work in this journal}

OncoTargets and Therapy is an international, peer-reviewed, open access journal focusing on the pathological basis of all cancers, potential targets for therapy and treatment protocols employed to improve the management of cancer patients. The journal also focuses on the impact of management programs and new therapeutic agents and protocols on

\section{Dovepress}

patient perspectives such as quality of life, adherence and satisfaction. The manuscript management system is completely online and includes a very quick and fair peer-review system, which is all easy to use. Visit http://www.dovepress.com/testimonials.php to read real quotes from published authors. 